ARTICLE

DOI: $10.1038 / s 41467-018-06148-7$

\title{
Lung colonization by Aspergillus fumigatus is controlled by ZNF77
}

\author{
Sara Gago (1) 1, Nicola L.D. Overton"1,5, Nagwa Ben-Ghazzi1, Lilyann Novak-Frazer (10 2,3, Nick D. Read', \\ David W. Denning ${ }^{4} \&$ Paul Bowyer ${ }^{1}$
}

Aspergillus fumigatus is a critical pathogen of humans. Exposure to A. fumigatus conidia occurs frequently but is normally cleared from the respiratory airways. In contrast, individuals with respiratory diseases are often highly colonized by fungi. Here, we use genome-edited epithelial cells to show that the genetic variant rs35699176 in ZNF77 causes loss of integrity of the bronchial epithelium and increases levels of extracellular matrix proteins. These changes promote A. fumigatus conidial adhesion, germination and growth. RNA-seq and LC/MS-MS analysis reveal rs35699176 upregulates vesicle trafficking leading to an increment of adhesion proteins. These changes make cells carrying rs35699176 more receptive to A. fumigatus in the early stages of infection. Moreover, patients with fungal asthma carrying rs35699176 $+/-$ have higher A. fumigatus loads in their respiratory airway. Our results indicate ZNF77 as a key controller of Aspergillus colonization and suggest its utility as a risk-marker for patient stratification.

\footnotetext{
${ }^{1}$ Manchester Fungal Infection Group, Division of Infection, Immunity and Respiratory Medicine, University of Manchester, CTF Building, 46 Grafton Street, Manchester M13 9NT, UK. ${ }^{2}$ Division of Infection, Immunity and Respiratory Medicine, School of Biological Sciences, Manchester Academic Health Science Centre, The University of Manchester and University Hospital of South Manchester NHS Foundation Trust, Manchester M23 9LT, UK. ${ }^{3}$ Mycology Reference Centre, ECMM Excellence Centre of Medical Mycology, Manchester University NHS Foundation Trust, Manchester M23 9LT, UK. ${ }^{4}$ National Aspergillosis Centre, Manchester Academic Health Science Centre, University Hospital of South Manchester NHS Foundation Trust, Manchester M23 9LT, UK. ${ }^{5}$ Present address: Clinical \& Experimental Pharmacology Group, CRUK Manchester Institute, University of Manchester, Manchester M20 4GJ, UK. Correspondence and requests for materials should be addressed to P.B. (email: paul.bowyer@manchester.ac.uk)
} 
$\mathrm{R}$ espiratory exposure to airborne Aspergillus fumigatus conidia is universal and unescapable ${ }^{1}$. In the healthy host, fungal spores are rapidly cleared from the respiratory airways. However in patients with an immune defect such as neutropenia, asthma or a cavitating lung disease, A. fumigatus spores can persist, colonize and lead to the development of aspergillosis ${ }^{2}$. Aspergillosis has recently been shown to cause more than 400,000 deaths each year ${ }^{3}$.

A. fumigatus colonization of the respiratory is associated with a higher risk of invasive aspergillosis and death in patients undergoing lung transplantation ${ }^{4,5}$ and high IgG levels in patients with chronic pulmonary aspergillosis ${ }^{6}$. Moreover, increased loads of $A$. fumigatus in the respiratory airways of asthmatic patients is associated with the development of allergic bronchopulmonary aspergillosis (ABPA), a progressive fungal allergic lung disease that significantly reduces the quality of life of over 5 million asthmatic people worldwide ${ }^{7-10}$. Aspergillus colonization of the lung epithelium in patients with ABPA leads to a hypersensitivity reaction to fungal antigens that promotes an IgE-mediated eosinophilic response, high mucus secretion and airway obstruction ${ }^{10}$. Fungal burden in ABPA varies considerably from individual to individual and colonization is associated with airway disease severity ${ }^{11}$. Abnormalities in the airway mucosal defences of patients with asthma and cystic fibrosis ${ }^{12}$, corticosteroid treatment ${ }^{13}$ or antibiotic misuse ${ }^{14}$ have been described as risk factors for Aspergillus allergic reaction and colonization in ABPA. However, fungal allergy only affects a low percentage of asthmatics in spite of constant exposure suggesting that ABPA might be due to an impaired genetic capability of some asthmatic patients to fend off fungal colonization ${ }^{15}$.

Currently, only a few polymorphisms in genes predicted to play a crucial role in the immune response to A. fumigatus have been assessed for their association with $\mathrm{ABPA}^{16-20}$. These genes all play a role in the adaptive immune response to fungi and are assumed to exacerbate fungal allergy in the context of atopic asthma.

The transcription factor ZNF77 belongs to the zinc finger protein family. Bioinformatics modelling suggests this transcription factor to control defensins, elastase and calmodulin expression, all potentially important for fungal clearance by the lung epithelium $^{21}$ (see supplementary note 1 for additional information). Here, we describe the role of rs35699176 in controlling fungal colonization in ABPA. This variant introduces a premature stop codon before the DNA binding region in the transcription factor ZNF77. Based on these results, we propose that ZNF77genotyping of patients with ABPA may be a useful risk-marker for fungal colonization.

\section{Results}

rs35699176 impairs epithelial integrity. To investigate the role of rs35699176 in fungal colonization, we genome-edited $16 \mathrm{HBE}$ bronchial epithelial cells to carry the rs35699176 variant using CRISPR/Cas9. The insertion of the mutation in the $16 \mathrm{HBE}$ genome was determined by PCR (Fig. 1a) indicating that the CRISPR/Cas9 system correctly introduces the specific mutation into $16 \mathrm{HBE}$ cells. ZNF77 gene expression was not significantly different $(P=0.94)$ in parental $16 \mathrm{HBE}$ and the genome-edited cell line (Fig. 1b).

We first investigated the role of rs35699176 in controlling epithelial monolayer integrity. $16 \mathrm{HBE}$ and $16 \mathrm{HBE}^{\mathrm{rs} 35699176}$ cell lines were seeded in transwell inserts and allowed to form monolayers over 9 days. We observed an $87 \%$ reduction of confluence in $16 \mathrm{HBE}^{\mathrm{rs} 35699176}\left(162.6 \pm 21.60 \mathrm{Ohms}\right.$ per $\left.\mathrm{cm}^{2}\right)$ compared to $16 \mathrm{HBE}$ cells $\left(917.5 \pm 103.138 \mathrm{Ohms}\right.$ per $\left.\mathrm{cm}^{2}\right)$ after 9 days $(P<0.001)$ (Fig. 1b). To investigate morphological changes associated with this loss of confluence, epithelial monolayers were visualised using live-cell confocal microscopy. Imaging of $16 \mathrm{HBE}^{\mathrm{rs} 3569917}$ epithelial monolayers demonstrated defective adhesion to substrate and loss of confluence (Fig. 1c, Supplementary Movies 1 and 2). To examine if this loss of confluence in $16 \mathrm{HBE}^{\mathrm{rs} 35699176}$ affects the bronchial epithelial interaction with A. fumigatus, we initially screened expression of genes (occludin, caveoline and E-cadherin) known to be involved in tight junction and cell adhesion component regulation. Surprisingly we observed that occludin expression doubled in 16 HBE ${ }^{\text {rs35699176 }}$ cells compared to $16 \mathrm{HBE}$. Occludin expression decreases rapidly after $A$. fumigatus exposure $(P<0.005)$. No changes in expression were detected in the other genes (Fig. 1d).

rs35699176 promotes A. fumigatus adhesion. Human lung epithelium employs several methods of defence to remove and destroy inhaled pathogens. Besides physical removal by mucociliary flow, epithelial cells can secrete a wide range of antimicrobial peptides and they can also act as non-professional phagocytes 22 . Moreover, they secrete chemotactic factors to recruit more specialized immune cells to contribute to fungal clearance ${ }^{23}$. Most clearance mechanisms mediated by epithelium and macrophages are effective against ungerminated conidia. The capability of $A$. fumigatus to more rapidly adhere, germinate and grow on the bronchial epithelium could lead to increased survival of the host immune response facilitating fungal colonization ${ }^{24}$.

Adhesion of $A$. fumigatus spores was $10.4 \%$ higher on $16 \mathrm{HBE}^{\mathrm{rs} 35699176}$ cells compared to $16 \mathrm{HBE}$ at $2 \mathrm{~h}$ post-infection $(P<0.001)$ (Fig. 2a). Similarly, adherence to extracellular matrix was $35 \%$ higher in $16 \mathrm{HBE}^{\mathrm{rs} 35699176}$ than $16 \mathrm{HBE}$ cells $(P<0.0001)$ and this was associated with higher concentration of extracellular matrix proteins in $16 \mathrm{HBE}^{\mathrm{rs} 35699176}$ cells $(P<0.00001)$ (Fig. $\left.2 \mathrm{~b}, \mathrm{c}\right)$.

The faster adhesion time observed for $A$. fumigatus conidia on $16 \mathrm{HBE}^{\mathrm{rs} 35699176}$ cells led to earlier A. fumigatus germination in our model. In order to rule out possible isolate-specific effects, six A. fumigatus isolates were tested for germination and adherence to the modified cell line. All six A. fumigatus strains tested were able to germinate $28.3 \pm 12.6 \mathrm{~min}$ earlier in the presence of $16 \mathrm{HBE}^{\mathrm{rs} 35699176}$ cells than in the presence of $16 \mathrm{HBE}$ cells (range $15-41 \mathrm{~min})(P<0.001)$ (Supplementary movies 3 and 4$)$ and to double overall hyphal extension at $9 \mathrm{~h}$ post-inoculation $(76.4 \pm$ $5.0 \mu \mathrm{m}$ in the presence of $16 \mathrm{HBE}$ cells compared to $157.7 \pm 10.7$ $\mu \mathrm{m}$ in the presence of $16 \mathrm{HBE}^{\mathrm{rs} 35699176}$ cells, $P<0.001$ ) (Fig. $2 \mathrm{c}, \mathrm{d}$ and Supplementary Figure 1). These growth changes in $A$. fumigatus led to a $6.51 \%$ increment of $A$. fumigatus-mediated cytotoxicity in the $16 \mathrm{HBE}^{\mathrm{rs} 35699176}$ cells $(P<0.05)$ determined by a lactate dehydrogenase assay at $16 \mathrm{~h}$ post-inoculation (Fig. 2e). Three other closely related pathogenic Aspergillus species, Aspergillus nidulans, Aspergillus terreus and Aspergillus niger, did not show increased growth in the presence of $16 \mathrm{HBE}^{\mathrm{rs} 35699176}$ cells using the same infection model (Fig. 2f).

To investigate the cause of differences in A. fumigatus adhesion germination and growth in the presence of the variant cell line we next measured the secretion of soluble factors and spore uptake amongst $16 \mathrm{HBE}$ and $16 \mathrm{HBE}^{\mathrm{rs} 35699176}$ cells. A. fumigatus germination rates in cell-free culture supernatants from $16 \mathrm{HBE}^{\mathrm{rs} 35699176}$ and $16 \mathrm{HBE}$ cell lines were also measured. $A$. fumigatus spore germination was $7.83 \%, 12.87 \%$ and $19.65 \%$ higher in $16 \mathrm{HBE}^{\mathrm{rs} 35699176}$ than in $16 \mathrm{HBE}$ at $4-$, 5- and 6 -h incubation, respectively $(P<0.001)$ (Fig. $2 \mathrm{~g}$ ). Linear regression analysis of the germination time points in cell-free-culture supernatants from $16 \mathrm{HBE}$ and $16 \mathrm{HBE}^{\mathrm{rs} 35699176}$ cells replicated these observations (Supplementary figure 2). Interestingly, spores incubated with $16 \mathrm{HBE}^{\mathrm{rs} 35699176}$ culture supernatants that had been heat-treated showed germination rates identical to spores 

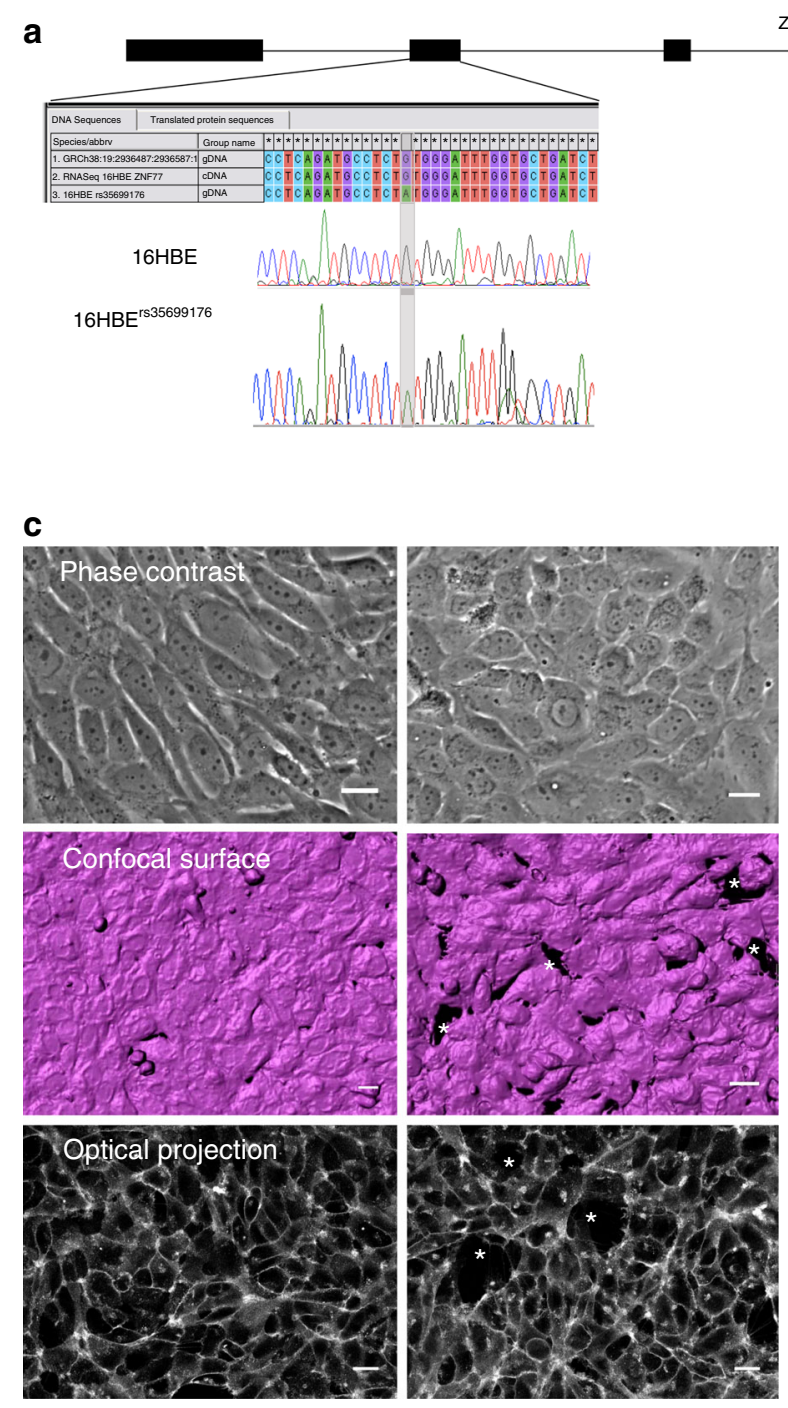

ZNF77 Chr19:2933218-2944971
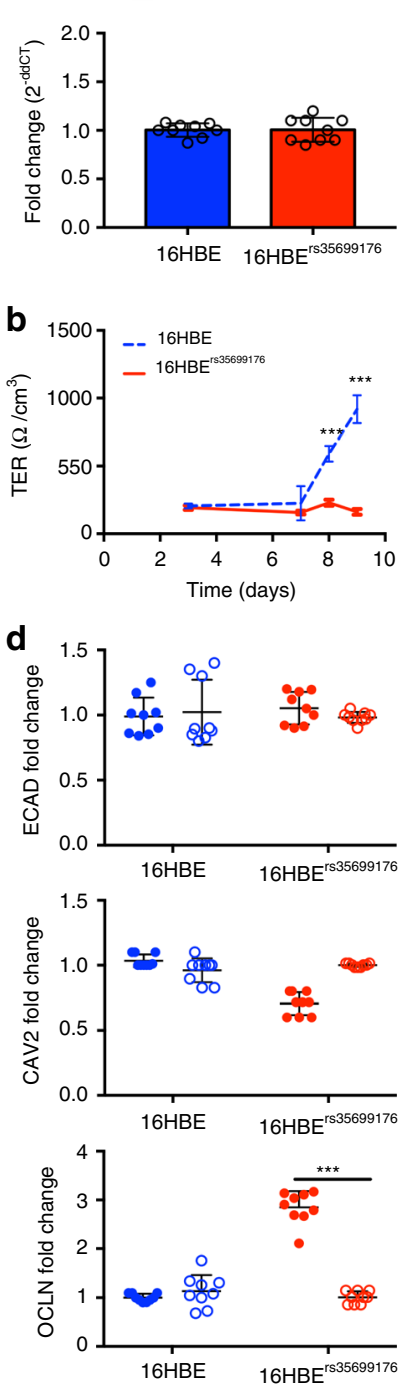

Fig. 1 Altered morphology and confluence of bronchial epithelial cells carrying rs35699176. a Schematic of the rs35699176 targeted region and sequences of the human ZNF77 locus, including the chromatogram derived from Sanger sequencing of the mutant allele. Gene expression of ZNF77 in 16HBE cells and $16 \mathrm{HBE}^{\mathrm{rs} 35699176}$ cell lines is equivalent (right panel). b Transepithelial electrical resistance (TER) does not increase after 8 days in monolayers formed by $16 \mathrm{HBE}^{\mathrm{rs} 35699176}$ cells (panel $\mathbf{b}$, solid line, ${ }^{\star \star \star} P<0.0001$ ) indicating failure to form confluent cell layers. c Microscopy reveals alterations in $16 \mathrm{HBE}{ }^{\text {rs35699176 }}$ monolayer morphology. Phase contrast microscopy shows rounded, non-adherent cells of 16HBErs35699176; confocal, surface rendered projection, stained with Cell Mask Deep Red shows holes in the monolayer and single optical section from projection. Images were processed using Metamorph and IMARIS v8.0.1 software. Asterisks denote lack of confluency. Scale bar represents $20 \mu \mathrm{m}$. d Fold change in gene expression of caveolin, occludin and E-cadherin genes after $6 \mathrm{~h}$ (solid columns) and $6 \mathrm{~h}$ (hashed columns) in $16 \mathrm{HBE}$ and $16 \mathrm{HBE}^{\text {rs } 35699176}$ cells co-cultured with A. fumigatus. Data in graphs are represented as mean \pm standard deviation of a minimum of three experiments performed in biological and technical triplicates. Differences in gene expression and transepithelial resistance for each time point were analysed using the Mann-Whitney $U$ test, ${ }^{\star \star \star} P<0.001$

incubated with $16 \mathrm{HBE}$ culture supernatants $(5 \%, 26 \%$ and $41 \%$ at 4-, 5- and 6-h co-incubation, respectively) suggesting the involvement of a protein factor mediating this phenotype (Supplementary figure 3).

Bronchial epithelial cells can act as non-professional phagocytes and internalize conidia via endocytosis and kill them via phagolysosome acidification. We found $16 \mathrm{HBE}^{\mathrm{rs} 356991716}$ cells internalized A. fumigatus conidia more efficiently at $2 \mathrm{~h}$ post-infection than $16 \mathrm{HBE}$ cells $(27.17 \%$ vs $37.5 \%, P<0.0001$ ) (Fig. 2h). This correlates with a higher percentage of adhesion to the genome-edited cell line. Germination of A. fumigatus spores results in exposure of spore surface proteins and carbohydrates that are recognized by host cell receptors ${ }^{25}$. However, the percentage of spore uptake was similar for $16 \mathrm{HBE}$ and $16 \mathrm{HBE}^{\mathrm{rs} 35699176}$ at later time points where germination had occurred in both systems suggesting that phagocytosis is ultimately similar in variant and parental cell lines.

We hypothesised that earlier A. fumigatus germination and growth could affect cytokine secretion and measured cytokine response at $6 \mathrm{~h}$ post-inoculation for $16 \mathrm{HBE}$ and $16 \mathrm{HBE}^{\mathrm{rs} 35699176}$. A. fumigatus exposure induced higher levels of IL-6 and IL-10 secretion in $16 \mathrm{HBE}^{\mathrm{r} 335699176}$ cells than in $16 \mathrm{HBE}$ cells. The stronger cytokine induction in $16 \mathrm{HBE}^{\mathrm{r} 335699176}$ cells could be due to a response to the earlier formation of A. fumigatus germlings and hyphae previously observed (Fig. 2i). 
a
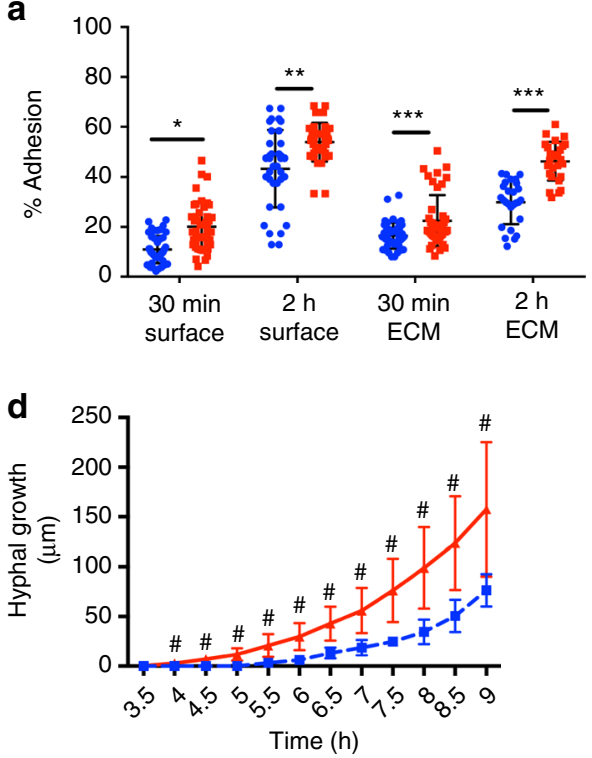

g

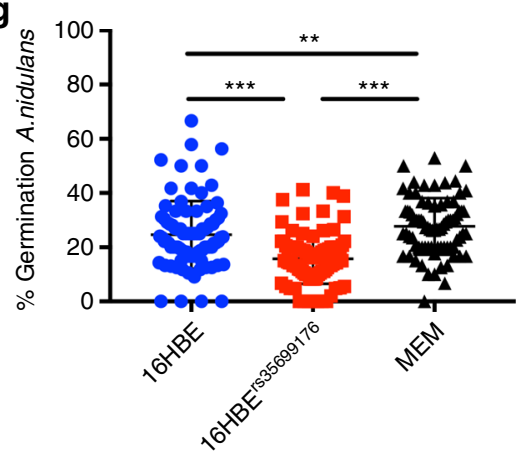

$\mathbf{h}$

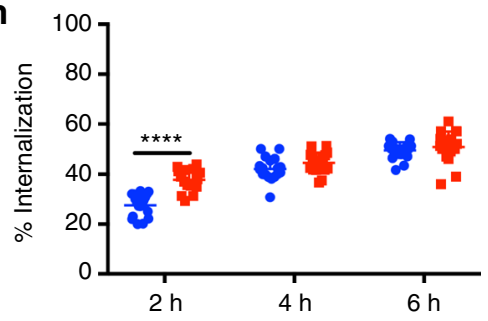

b

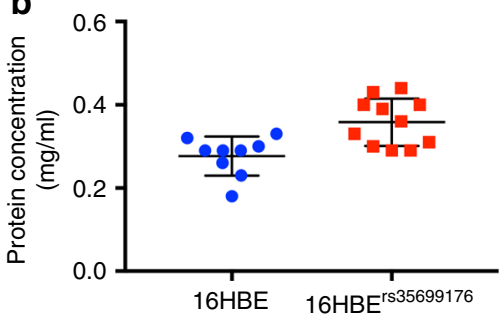

C
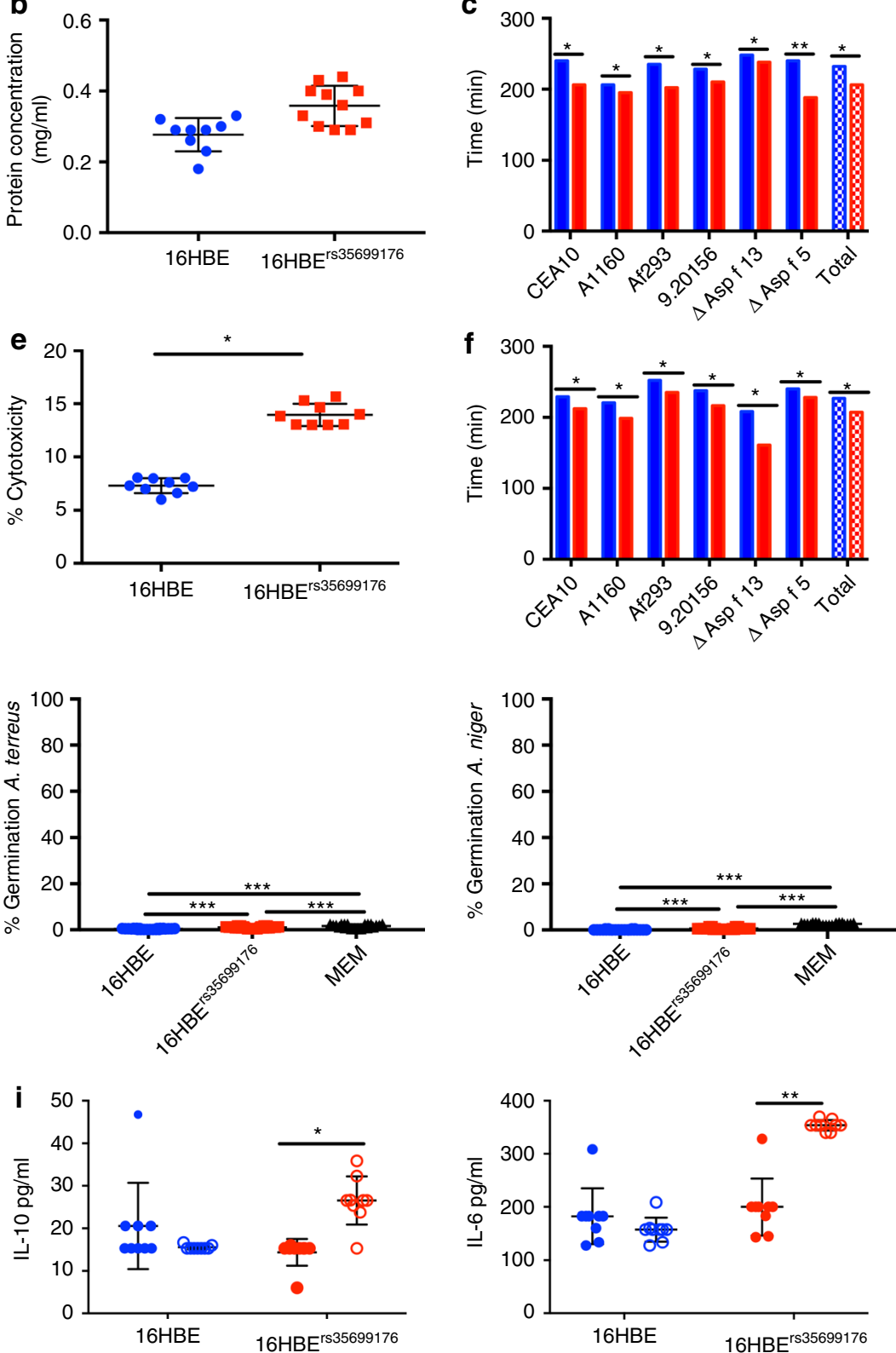

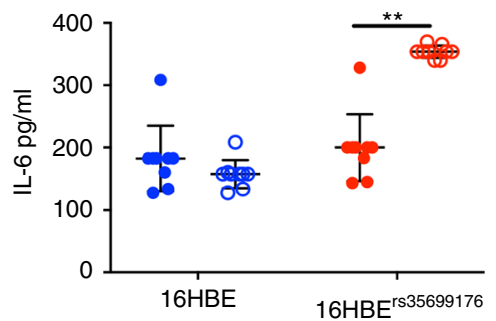

Fig. 2 Changes in the integrity of $16 \mathrm{HBE}^{\text {rs } 35699176}$ epithelial monolayers influence A. fumigatus infection. Blue: $16 \mathrm{HBE}$; Red: $16 \mathrm{HBE}$ rs35699176. a A. fumigatus conidia shows greater adhesion to cells and extracellular matrix components of $16 \mathrm{HBE}^{\text {rs } 35699176}$ cell lines at 30 min and $2 \mathrm{~h}$ after infection as determined by using two-way ANOVA with Sidak multiple comparison tests. b Extracellular matrix protein concentration is higher in $16 \mathrm{HBE}^{\mathrm{rs} 35699176}$ than $16 \mathrm{HBE}$ cells. Differences between protein concentrations were performed using an unpaired T-test after performing normality test using D'Agostinho and Pearson normality test. c Germination time for A. fumigatus conidia inoculated onto $16 \mathrm{HBE}^{\mathrm{rs}} 35699176$ (red) monolayers compared to $16 \mathrm{HBE}$ (blue) is decreased in the variant cell line. Differences were analysed using two-way ANOVA with multiple comparison test. $\mathbf{d}$ A. fumigatus CEA10 hyphal extension is increased in $16 \mathrm{HBE}^{\mathrm{rs}} 35699176$ compared to $16 \mathrm{HBE}$ cells. Differences were analysed using an unpaired T-test after normal distribution being confirmed using the D'Agostinho and Pearson normality test. e Lactate dehydrogenase (LDH) assays show increased A. fumigatus CEA10 cytotoxicity in $16 \mathrm{HBE}^{\mathrm{rs} 35699176}$ after $20 \mathrm{~h}$ infection. Differences were analysed using a non-parametric Mann-Witney test post-D'Agostinho and Pearson normality test. $\mathbf{f}$ Germination time of A. fumigatus spores in conditioned culture supernatant is reduced in $16 \mathrm{HBE}^{\mathrm{rs}} 35699176$ cell lines (red) at $6 \mathrm{~h}$ infection time. Differences were analysed using a two-way ANOVA with multiple comparison test. $\mathbf{g}$ Significantly reduced spore germination of $A$. nidulans, A. flavus and A. terreus in 16HBE and $16 \mathrm{HBE}^{\mathrm{rs}} 35699176$ cell supernatants compared to A. fumigatus (Supplementary Figure 2). Differences were analysed using one-way ANOVA with Dunnet's multiple comparison test. $\mathbf{h}$ A. fumigatus conidia are more effectively internalized by cells carrying the variant rs 35699176 than in $16 \mathrm{HBE}$ controls at $2 \mathrm{~h}$ coculture. Differences were analysed using two-way ANOVA with multiple comparison test. $\mathbf{i}$ Increased IL-10 and IL-6 release in $16 \mathrm{HBE}^{\mathrm{rs}} 356999176$ cells in response to A. fumigatus exposure for $6 \mathrm{~h}$. Transparent fill denotes A. fumigatus exposure. Differences were analysed using two-way ANOVA with multiple comparison test. Data in graphs are represented as mean \pm standard deviation. Means were compared; ${ }^{\star} P<0.05 .{ }^{\star \star} P<0.001,{ }^{\star \star \star} P<0.0001$ 
a

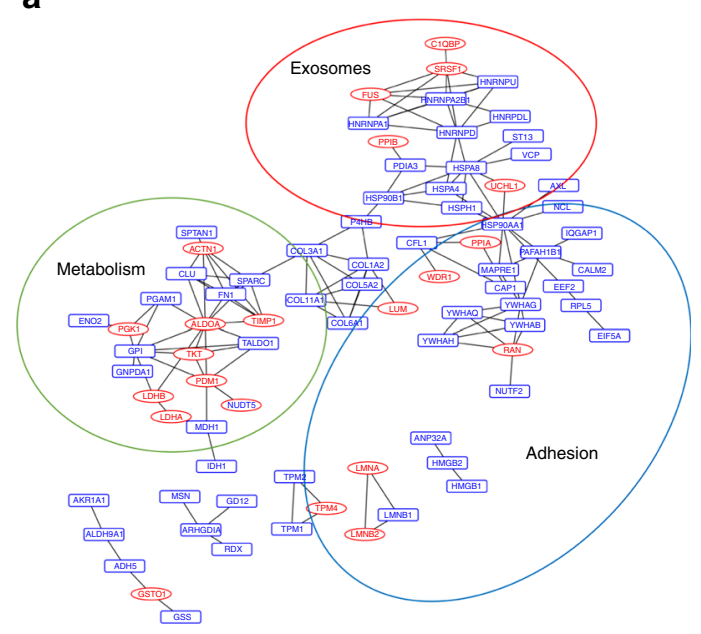

b
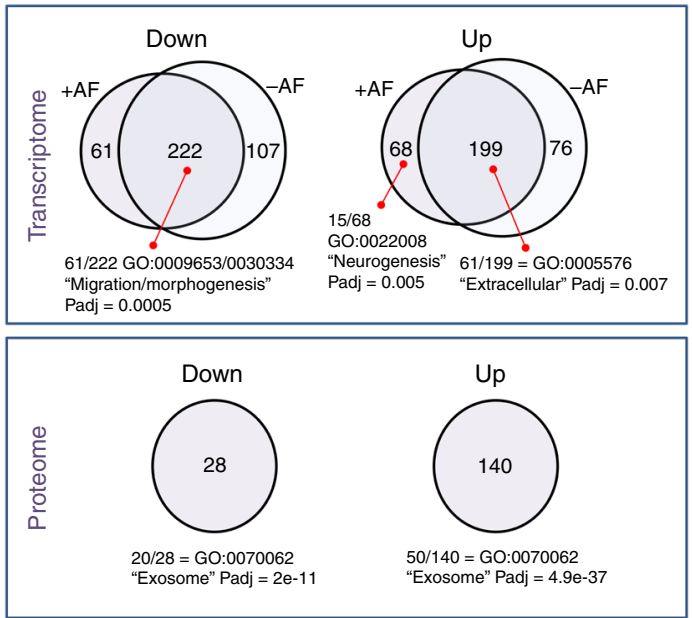

Fig. 3 Secretome and RNA-seq analysis of $16 \mathrm{HBE}^{\text {rs } 35699176}$ show altered profiles in adhesion molecules. a Analysis of protein-protein interaction networks demonstrates higher secretion in the $16 \mathrm{HBE}^{\mathrm{rs} 35699176}$ cell line of proteins involved in cell metabolism regulation and exosome pathways. Red ellipses represent proteins detected directly by mass spectrometry while the blue rectangles are proteins induced by the bioinformatics modelling within each network. b Functional category enrichment analysis of the differentially expressed and secreted proteins in $16 \mathrm{HBE}$ and $16 \mathrm{HBE}^{\mathrm{rs}} 35699176$ bronchial epithelial with and without $A$. fumigatus challenge. Experiments were performed in biological replicates. Gene Ontology analyses were performed using strings. Statistical significance was calculated using strings

ZNF77 regulates extracellular matrix expression. To investigate the role played by proteins secreted by bronchial epithelial cells in controlling Aspergillus germination, we characterized the secretome of serum-starved cell culture supernatants from $16 \mathrm{HBE}$ and $16 \mathrm{HBE}^{\mathrm{rs} 35699176}$ cells. Protein levels were measured using LCMS/MS revealing a total of 234 significantly differentially secreted proteins (Supplementary figure 4, Supplementary data 1). After filtering ( $\log _{2}$ fold change $>2$ and $P<0.05$ ), comparative protein abundance analysis reveals 140 proteins upregulated and 21 proteins down-regulated in 16HBErs35699176. Network and ontology analysis of the dysregulated proteins in $16 \mathrm{HBE}^{\mathrm{rs}} 35699176$ demonstrated them to be involved in cell adhesion (GO:0044421, $\left.P_{\text {adj }}=1.63 \mathrm{e}-18\right)$, metabolism (GO:00463464, GO:0044712, GO:0009132, $P<0.0001)$ and exosome (GO:0070062; $P_{\text {adj }}=$ $2.19 \mathrm{e}-22)$ pathways. All of these are known to be important in regulating the immune response, cell remodelling and signalling in asthma ${ }^{26-28}$. Gene Ontology (GO) analyses demonstrated a significant enrichment of extracellular exosome terms (GO:0070062) for 20/28 down-regulated proteins and 50/140 upregulated proteins in $16 \mathrm{HBE}^{\mathrm{rs} 35699176}\left(P_{\mathrm{adj}}<2 \mathrm{e}-11\right)$ (Fig. 3a, b). Interestingly, proteins facilitating pathogen binding such as collagens, ficolins, cofilin and lectin binding proteins were more highly represented in $16 \mathrm{HBE}^{\mathrm{rs}} 35699176$ and could credibly explain the increased A. fumigatus adhesion and spore uptake phenotypes of $16 \mathrm{HBE}^{\mathrm{rs} 35699176}$ cells. However, an observed downregulation of proteins involved in oxidative processes such as lactotransferrin and calmodulin could be important in limiting pathogen clearance in the cell line carrying the rs35699176 genotype. We were not able to observe any significant differences in secretome composition between $16 \mathrm{HBE}$ and $16 \mathrm{HBE}^{\text {rs35699176 }}$ at 6 h post-inoculation with $A$. fumigatus.

Since the effect of $A$. fumigatus inoculation on epithelial cells at $6 \mathrm{~h}$ could be solely transcriptional we then performed RNAseq analysis on $16 \mathrm{HBE}$ and $16 \mathrm{HBE}^{\mathrm{rs} 35699176}$ cells after $6 \mathrm{~h} A$. fumigatus exposure (Supplementary data 2, 3, 4 and 5). Five of the most strongly regulated genes were validated using qRT-PCR (Supplementary figure 3). After interaction analysis in DESEQ2, we found that inoculation caused the same transcriptional changes in $16 \mathrm{HBE}$ and $16 \mathrm{HBE}^{\mathrm{rs} 35699176}$ cells but that the transcriptomes of the two un-inoculated cell lines were significantly different.

GO analysis of the down-regulated genes in $16 \mathrm{HBE}^{\mathrm{rs} 35699176}$ cell lines demonstrated a significant enrichment of genes involved in migration and morphogenesis (61/222 genes, GO:0009653 and GO:0030334, $\left.P_{\mathrm{adj}}=0.0005\right)$ that might be associated with the altered epithelium structure. Up-regulated genes in $16 \mathrm{HBE}^{\mathrm{rs} 35699176}$ compared to $16 \mathrm{HBE}$ cells, were enriched for extracellular region components (GO:0005576, $P_{\text {adj }}=0.007$ ). Comparison of difference in gene expression between $16 \mathrm{HBE}$ cells and $16 \mathrm{HBE}^{\mathrm{rs} 35699176}$ cells at $6 \mathrm{~h}$ A. fumigatus infection, demonstrated an enrichment on genes involved in neurogenesis $\left(15 / 68\right.$ genes GO:0022008, $\left.P_{\text {adj }}=0.005\right)$.

We found a significant $\left(P_{\mathrm{adj}}<0.001\right)$ enrichment of components leading to the activation of the immune response in $16 \mathrm{HBE}$ controls vs $16 \mathrm{HBE}$ inoculated with A. fumigatus including: Fc receptor mediated inhibitory signalling pathway (GO:0002767), positive regulation of interleukin-23 production (GO:0032747), positive regulation of $\mathrm{NAD}(\mathrm{P}) \mathrm{H}$ oxidase activity (GO:0033864), phagosome acidification (GO:0090383) or regulation of I-kappaB kinase/NF-kappaB signalling (GO:0043122). However, no changes in gene expression between uninfected $16 \mathrm{HBE}^{\mathrm{rs} 35699176}$ and $6 \mathrm{~h} \mathrm{~A}$. fumigatus challenged $16 \mathrm{HBE}^{\mathrm{rs} 35699176}$ cells were observed suggesting a permissive role of the bronchial epithelium to A. fumigatus in patients carrying the rs35699176 genetic variant (Supplementary data 3 and 4).

rs35699176 promotes airway colonization. We explored the correlation between the rs35699176 genotype and fungal colonization in two different cohorts of patients with known fungal loads in respiratory samples (Tables 1 and 2). A. fumigatus burdens, measured by genome equivalents, were 15 times higher in bronchoalveolar lavage fluid from patients carrying rs35699176 $6^{+l-}(P<0.05)$. Sixty percent $(4 / 6$ vs $0 / 15)$ of patients with $>100 \mathrm{~A}$. fumigatus genomes per $\mathrm{ml}$ of $\mathrm{BAL}$ carried the rs35699176 $+/-(P=0.0006)$ (Fig. 4d). 
Table 1 Demographics of patients with known fungal loads determined by mycobiome analysis

\begin{tabular}{|c|c|c|c|c|}
\hline & Total & rs35699176-/- & rs35699176+/- & $P$-value \\
\hline \multicolumn{5}{|l|}{ ABPA $(\boldsymbol{n}=7)$} \\
\hline $\mathrm{BMI}$ & $25.71 \pm 2.64$ & $25.62 \pm 2.73$ & $25.78 \pm 2.57$ & ns \\
\hline Smokers or ex-smokers & $14.28 \%$ & $0 \%$ & $25 \%$ & ns \\
\hline Forced vital capacity $(F \vee C, I)$ & $3.11 \pm 0.85$ & $2.91 \pm 0.62$ & $3.21 \pm 0.95$ & ns \\
\hline $\mathrm{FEV} / \mathrm{FEC}(\%)$ & $54.78 \pm 14.08$ & $50.31 \pm 7.51$ & $58.14 \pm 16.65$ & ns \\
\hline Total lgE > $1000 \mathrm{IU}$ & $28 \%$ & $33 \%$ & $25 \%$ & ns \\
\hline $\mathrm{BMI}$ & $25.7 \pm 4$ & $25.7 \pm 4$ & $\mathrm{nf}$ & $\mathrm{nf}$ \\
\hline Smokers or ex-smokers & $16.66 \%$ & $16.66 \%$ & $\mathrm{nf}$ & $\mathrm{nf}$ \\
\hline Forced expiratory volume (FEV, I) & $2.14 \pm 0.81$ & $2.14 \pm 0.81$ & $\mathrm{nf}$ & nf \\
\hline Forced vital capacity $(F \vee C, I)$ & $3.71 \pm 1.6$ & $3.71 \pm 1.6$ & $\mathrm{nf}$ & $\mathrm{nf}$ \\
\hline $\mathrm{FEV} / \mathrm{FEC}(\%)$ & $56.13 \pm 9.98$ & $56.13 \pm 9.98$ & $\mathrm{nf}$ & $\mathrm{nf}$ \\
\hline Total IgE > $1000 \mathrm{IU}$ & $0 \%$ & $0 \%$ & $\mathrm{nf}$ & $\mathrm{nf}$ \\
\hline Forced vital capacity (FVC, I) & $3.52 \pm 1.02$ & $3.52 \pm 1.02$ & $\mathrm{nf}$ & nf \\
\hline $\mathrm{FEV} / \mathrm{FEC}(\%)$ & $59.65 \pm 9.75$ & $59.65 \pm 9.75$ & $\mathrm{nf}$ & nf \\
\hline Total $\operatorname{lgE}>1000 \mathrm{IU}$ & $0 \%$ & $0 \%$ & $\mathrm{nf}$ & nf \\
\hline $\begin{array}{l}\text { log10 Aspergillus genome equivalents } \\
\text { Healthy controls }(\boldsymbol{n}=4)\end{array}$ & $1.27 \pm 0.31$ & $1.27 \pm 0.31$ & $\mathrm{nf}$ & $\mathrm{nf}$ \\
\hline $\mathrm{BMI}$ & $32 \pm 9$ & $32 \pm 9$ & $\mathrm{nf}$ & $\mathrm{nf}$ \\
\hline Smokers or ex-smokers & $0 \%$ & $0 \%$ & $\mathrm{nf}$ & $\mathrm{nf}$ \\
\hline Forced expiratory volume (FEV, I) & $\mathrm{n} / \mathrm{a}$ & $\mathrm{n} / \mathrm{a}$ & $\mathrm{nf}$ & $\mathrm{nf}$ \\
\hline Forced vital capacity (FVC, I) & $\mathrm{n} / \mathrm{a}$ & $\mathrm{n} / \mathrm{a}$ & $\mathrm{nf}$ & $\mathrm{nf}$ \\
\hline $\mathrm{FEV} / \mathrm{FEC}(\%)$ & $\mathrm{n} / \mathrm{a}$ & $\mathrm{n} / \mathrm{a}$ & $\mathrm{nf}$ & nf \\
\hline Total $\lg E>1000 \mathrm{IU}$ & $0 \%$ & $0 \%$ & $\mathrm{nf}$ & nf \\
\hline log10 Aspergillus genome equivalents & $1.05 \pm 0.28$ & $1.05 \pm 0.28$ & $\mathrm{nf}$ & $\mathrm{nf}$ \\
\hline
\end{tabular}

Table 2 Demographics of patients with ABPA and known fungal loads determined by Aspergillus-specific qPCR

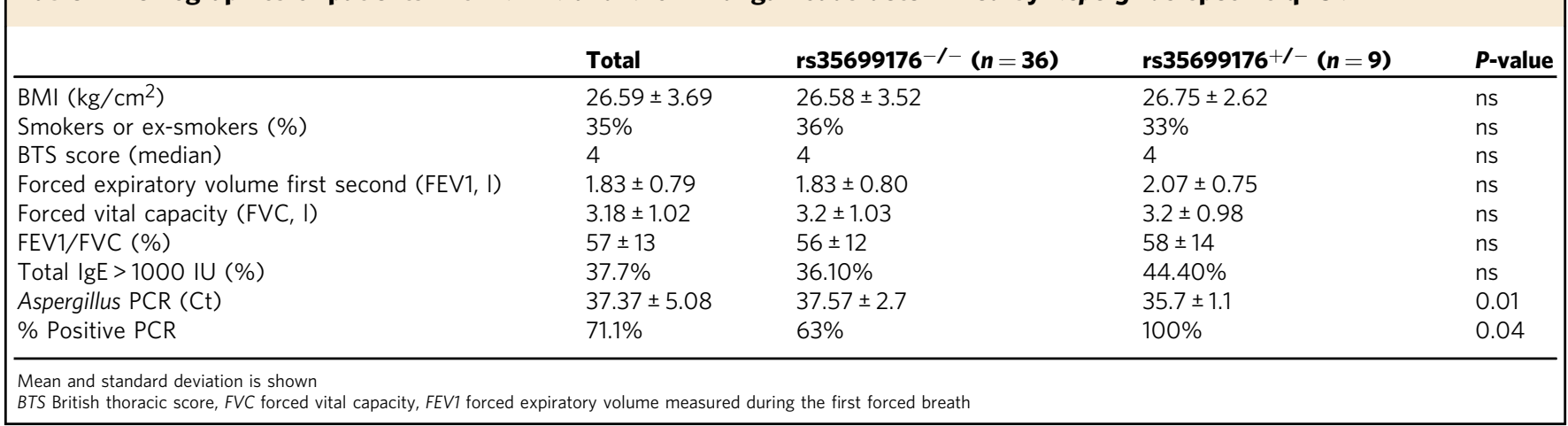

As it is not possible to systematically bronchoscope this patient group we then investigated the association of rs35699176 with fungal burden in sputum measured using qPCR. Forty-five patients with ABPA were tested by qPCR (Fig. 4e). Twenty-eight percent of patients (9/32) with an Aspergillus positive sputum PCR and $0 \%(0 / 13)$ patients with an Aspergillus negative sputum PCR carried rs35699176 ${ }^{+/-}(P=0.036)$. Aspergillus-specific qPCR Ct values in rs35699176 ${ }^{+/-}$patients were significantly higher than in those with $\mathrm{rs} 35699176^{+/+}$, indicating that rs35699176 doubles fungal loads in sputum derived from the upper respiratory airways. Asthma severity measured by BTS score, FEV1 and FVC were not significantly different between groups (Table 1).

\section{Discussion}

Increased A. fumigatus colonization of the airway epithelium is associated with worse outcome in patients with fungal disease $\mathrm{e}^{29}$. Given that exposure to A. fumigatus spores is constant it has been theorised that colonization and infection are determined by host genetic factors. In the case of ABPA, this phenotype could be partially explained by the impaired airway epithelium function in 

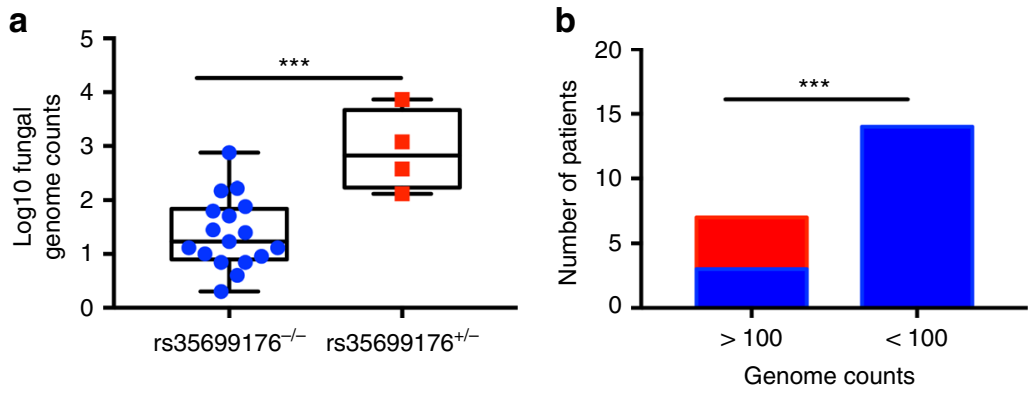

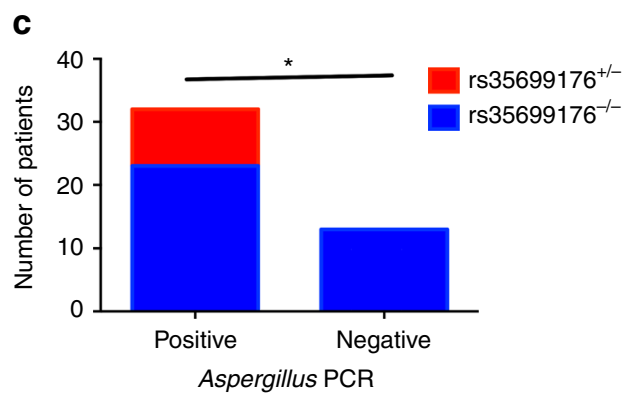

Fig. 4 Individuals heterozygous for rs35699176 have higher lung A. fumigatus burden. a, b Correlation between rs35699176+/- and fungal load in patient bronchoalveolar samples with fungal loads expressed as genome counts. Boxplots represent median and maximum and minimum values. Comparisons were performed using Fisher exact test. c Association between a positive Aspergillus PCR in sputum and rs35699176+/-. Comparisons were performed using Fisher exact test. ${ }^{\star} P<0.05,{ }^{\star \star} P<0.001,{ }^{\star \star \star} P<0.0001$

asthma but not all asthmatic patients develop $\mathrm{ABPA}^{10}$. We observed that a genetic variant, rs35699176, causing a premature stop codon in ZNF77 leads to a pathophysiological mechanism whereby A. fumigatus colonization of the respiratory airways is increased. Bronchial epithelial cells carrying rs35699176 showed strongly altered levels of cell matrix components and were more permissive to A. fumigatus promoting greater adhesion, germination and growth. Importantly this observation was validated in patients with ABPA where strongly increased fungal burdens were associated with the presence of the variant, suggesting the utility of rs35699176 genotyping as a colonization risk-marker in ABPA.

Compromised epithelial barrier function is associated with the development of atopic asthma possibly due to increased tissue penetrance of allergens and inflammatory factors ${ }^{30,31}$. The lack of confluence of cells carrying the rs35699176 genetic variant could facilitate passage of A. fumigatus antigens into the airway tissue, leading to immune activation and ultimately to expression of ABPA. Tight junction and adhesion proteins provide structural integrity to the epithelial barrier, block allergen influx, provide resistance to pathogens and control cell homeostasis ${ }^{22}$. A wide number of allergic diseases are exacerbated by a loss of epithelial barrier function associated to changes in the expression of filaggrin $^{32}$, claudin- ${ }^{33}$, adhesion and tight junction proteins ${ }^{34,35}$.

Interestingly, occludin was upregulated in $16 \mathrm{HBE}^{\mathrm{rs} 35699176}$ compared to $16 \mathrm{HBE}$ cells but it was rapidly downregulated after Aspergillus challenge. This suggests that $16 \mathrm{HBE}^{\mathrm{rs} 35699176}$ cells might over-express occludin to try to compensate for the downregulation of other genes involved in junction formation (e.g. GJB3, CDH1, PCDHGA4) and morphogenesis (e.g. TMEM217, TGM2, IGF2). A. fumigatus spores undergo several morphological changes during their interaction with the lung epithelium $^{36}$. Early after inhalation, A. fumigatus conidia will contact the airway epithelium where they swell and germinate to form hyphae. Native and swollen spores can be internalized before undergoing germination and hyphal growth within epithelial cells ${ }^{23}$. Moreover, factors secreted by epithelial cells (defensins, PTX3, etc.) control the initial steps of the A. fumigatus clearance response $\mathrm{s}^{37,38}$.

Our results indicate that an upregulation of gene expression and the synthesis of proteins involved in the extracellular region of the cells such as collagens, ficolin, lectins, laminin or integrins in $16 \mathrm{HBE}^{\mathrm{rs} 35699176}$ cells facilitates an earlier A. fumigatus adhesion to the host surface $26,39-41$. Those components can act like a glue to anchor the fungal spore to host. Lung epithelial cells are recognized as non-professional phagocytes and can contribute to spore clearance via endocytosis $27,28,42$. Earlier adhesion to the host surface in rs35699176 $6^{+/+}$cells correlates with an enhanced spore uptake from those cells $2 \mathrm{~h}$ after exposure. However spore phagocytosis is the same for parental and variant cell lines after 4 h. Spore internalisation is dependent on two crucial regulators of the actin dynamics of the host, phospholipase $\mathrm{D}^{43}$ and cofilin- $1^{42}$, which are activated after exposure to $1,3-\beta-\mathrm{D}$ glucan on the surface of swollen or germinating conidia and hyphae. We found that cofilin-1 and ARC were significantly overexpressed in unchallenged $16 \mathrm{HBE}^{\mathrm{rs} 35699176+/+}$ cells and this might explain why $16 \mathrm{HBE}^{\mathrm{rs} 35699176+/+}$ cells could more effectively phagocytose fungal spores at $2 \mathrm{~h}$ but not at later time points ${ }^{44}$. In this model, the increased fungal burden arises from early germination of noninternalized spores rather than from escape from phagocytosis. No host-derived growth promotion factors have been described previously for moulds although factors modulating bacterial and Candida growth have been observed ${ }^{45-47}$. The only host factors described that might modulate Aspergillus germination and growth are limited to human glycogen synthase kinase 3 activity, corticosteroid treatment or smoking status ${ }^{13,48,49}$.

The increase in adhesion and germination caused by rs35699176 is specific to A. fumigatus and is not observed for other closely related pathogenic Aspergilli. A. fumigatus is the main cause of fungal allergy but the other Aspergillus species are also frequently found in the environment and cause the same spectrum of allergic, chronic and invasive diseases ${ }^{2}$. The lack of germination and growth responses in the other Aspergillus species might explain the predominance of $A$. fumigatus in aspergillosis.

Bronchial epithelial cells carrying rs35699176 responded with a stronger inflammatory IL-6 and IL-10 response to A. fumigatus conidia after infection. Interestingly, those cytokines are released in response to fungal proteases released by growing hyphae $e^{50,51}$. The faster exposure of glucans and earlier hyphal development observed after inoculation of $16 \mathrm{HBE}^{\mathrm{rs} 35699176}$ cells with $A$. fumigatus spores could explain why those cytokines can be detected in cell culture supernatants from $16 \mathrm{HBE}^{\mathrm{rs} 35699176}$ cells but not the parental cell line. The faster production of cytokines may have an important role in determining fungal burden at later time points. It has recently described that a genetically conditioned overexpression of IL-10 predisposes to invasive aspergillosis by suppressing the anti-Aspergillus response of macrophages ${ }^{52}$. Additionally, high serum levels of IL-10 in patients with cystic fibrosis are associated with Aspergillus colonization and $\mathrm{ABPA}^{53}$.

Although low-level colonization of the respiratory airways by A. fumigatus is universal ${ }^{54}$, patients with $\mathrm{ABPA}$ have higher fungal loads in their respiratory airways. Antifungal treatment is not considered primary therapy in ABPA, but azole treatment is useful in decreasing fungal burdens and minimizing exacerbations ${ }^{10,55}$ and a recent trial of azole therapy for severe asthma in the context of fungal sensitisation showed a strong effect on patient quality of life score. Here, we showed that patients 
heterozygous for rs35699176 have higher fungal burdens in the upper respiratory airways in both BAL and sputum samples. Although this phenotype did not correlate with worse asthma outcome in our exploratory cohorts, patients with the rs35699176 variant frequently carry elevated levels of allergenic fungus and therefore could benefit from antifungal treatment.

Our results show that in normal individuals ZNF77 prevents fungal persistence in the airways by regulating epithelial integrity and controlling the secretion of proteins, which modulate pathogen adhesion to the bronchial epithelium and extracellular matrix $^{56,57}$. The permissive response of the bronchial epithelium to A. fumigatus resulting from rs35699176 can contribute to chronic inflammation and the development of allergy through increased fungal burden. Although we show direct effects of rs35699176 genetic variant on fungal adhesion and growth on $16 \mathrm{HBE}$ cells, the effects of an altered epithelium in lung tissue are likely to be more complex as fungi will be able to access the basal lamina and other cell types will be present at sites of colonization or infection. The fact that we did not find patients homozygous for rs35699176 suggests that this could be lethal although the low frequency of the allele means that our study population is likely to be too small to observe homozygous individuals. Genome-editing tools available at the time this work was carried out did not allow for the recreation of heterozygous mutations. Moreover, a limitation of the epithelial cell model is that it does not currently allow longer-term experiments that might more accurately affect colonization. Hence the variant phenotype may only be accessible using homozygous variants. Longitudinal studies to correlate the rs35669176 genotype and Aspergillus disease are required to assess other factors that may affect colonization. Development of new strategies to modulate $A$. fumigatus adherence and colonization in ABPA might be a useful therapeutic avenue for individuals carrying the rs35699176 genotype.

\section{Methods}

Generation of 16HBE genome-edited bronchial epithelial cells. To study the biological function of the genetic variant rs35699176 in fungal colonization discovered in a whole exome sequencing study ${ }^{58}$ (see Supplementary note 1 and Supplementary table 1), we developed an in vitro model using genome-edited $16 \mathrm{HBE}$ bronchial epithelial cells ${ }^{59}$. $16 \mathrm{HBE}$ cells were a gift from Dr. D.C. Gruenert, University of California ${ }^{60}$. Mycoplasma contamination testing was performed by the University of Manchester cell culture facilities. To ensure that ZNF77 function and sequence alteration was correct in this cell line, we sequenced the region surrounding the variant and also performed variant calling from RNAseq data obtained in our laboratory as part of a previous study. Cell guides for targeting this region were designed by analysing a $1 \mathrm{~kb}$ genomic region surrounding the rs35699176 genetic variant (http://www.ensembl.org/index.html) and choosing Protospacer adjacent motif (PAM) sequences close to the genetic variant with ChopChop Software (https://chopchop.rc.fas.harvard.edu/). The selected CRISPR/ Cas9 guide was directed to the genomic region Chr19: 2936525-2936547 as this region had no predicted off-target effects. Oligonucleotides containing the CRISPR/ Cas9 guides were synthetized by Eurofins Genomics (Hamburg, Germany) (Supplementary Table 2). Guides were cloned into the GeneArt CRISPR Nuclease Vector with OFP Reporter Kit (Invitrogen, Paisley, UK) according to the manufacturer's instructions. Ten clones were sequenced by using U6 primers provided by the manufacturer. Control oligo included in the kit and pUC19 were used as transformation controls. Qiagen Midiprep plasmid kits (Qiagen, Manchester, UK) were used to isolate plasmid DNA.

To be able to introduce the specific genetic variant (rs35699176) in 16HBE cells, a single strand donor repair template $(138 \mathrm{bp})$ was designed and purchased from IDT Technologies (Supplementary Table 2). The donor template contains the specific genetic variant and a non-sense mutation in the PAM sequence to avoid Cas9 cutting the repair template, for this purpose the TGG-PAM sequence was changed to TGA which is synonymous in ZNF77. Ultramer oligos were used at a $10 \mu \mathrm{M}$ final concentration (IDT Technologies, Coralville, USA) (Supplementary Table 2).

16HBE cells were maintained in supplemented Minimum Essential Medium (MEM, Sigma, Poole, UK) with $10 \%$ FBS, $1 \%$ L-glutamine and $1 \%$ penicillin streptomycin. Cells were seeded at $2 \times 10^{5}$ cells per well in a 24 -well plate and incubated at $37^{\circ} \mathrm{C}, 5 \% \mathrm{CO}_{2}$ for $16 \mathrm{~h}$. Before transfection, medium was removed completely and replaced with MEM containing $1 \% \mathrm{~L}$-glutamine and cells were incubated for an extra $2 \mathrm{~h}$ at $37^{\circ} \mathrm{C}, 5 \% \mathrm{CO}_{2}$. Each well was transfected with $500 \mathrm{ng}$ of plasmid and 1 pmol repair template using Lipofectamine 3000 reagent according to the manufacturer's instructions. Four hours after transfection, medium was changed with supplemented MEM. Toxicity controls were included in optimization experiments. Following transfection $(48 \mathrm{~h})$ cells were sorted and incubated for 2-3 weeks for clonal expansion. Those clones which were able to grow were scaled up in culture and analysed by sequencing. The insertion of the mutation was confirmed by sequencing a 663 bp region in ZNF77. Genome DNA from transfected cells was isolated by using Gentra Pure DNA kit (Qiagen, Manchester, UK) according to the manufacturer's instructions. PCR reactions were performed in $25 \mu \mathrm{l}$ final volume PCR mix containing $1 \times$ MasterMix (Promega, Southampton, UK), $0.5 \mu \mathrm{M}$ of each primer (rs35699176-3 and rs35699176-4) and $10 \mathrm{ng}$ of DNA. Samples were amplified using the following cycling parameters: an initial cycle of $2 \mathrm{~min}$ at $95^{\circ} \mathrm{C}$, followed by $30 \mathrm{cycles}$ of $30 \mathrm{~s}$ at $95^{\circ} \mathrm{C}, 30 \mathrm{~s}$ at $58^{\circ} \mathrm{C}$, and $30 \mathrm{~s}$ at ${ }^{\circ} 68$ C, with a final cycle of $10 \mathrm{~min}$ at $68^{\circ} \mathrm{C}$. Reaction products were analysed in a $2 \%$ agarose gel and purified using QIAquick PCR Purification Kit (Qiagen,

Manchester, UK) and sequenced by Eurofins genomics. The ZNF77 gene sequence available in Ensembl GrCh38 and the sequence of the ZNF77 gene in a 16HBE background were used as reference. The effect of the insertion of the rs 35699176 genetic variants on ZNF77 gene expression was also evaluated. RNA was extracted using the RNAeasy kit (Qiagen, Manchester, UK). ZNF77 gene expression was evaluated by using primers ZNF77_2934825 and ZNF_2936494 which allowed for specific amplification of 100 bp of ZNF77 mRNA (Supplementary Table 2). The GAPDH gene was used as a housekeeping gene (Supplementary Table 2). Reactions were performed in a $20 \mu$ f final volume PCR mix containing $1 \times$ SensiFASTM SYBR $^{\circledast}$ Hi-ROX One-Step Mix (Bioline Reagents, London, UK), $0.2 \mu \mathrm{l}$ of reverse transcriptase, $0.4 \mu \mathrm{l}$ of ribosafe inhibitor, $500 \mathrm{nM}$ of each primer and $40 \mathrm{ng}$ of RNA. For reverse transcription reactions, samples were incubated for $10 \mathrm{~min}$ at $50^{\circ} \mathrm{C}$. Then, for PCR amplification, samples were denatured for $2 \mathrm{~min}$ at $95^{\circ} \mathrm{C}$ followed by 40 cycles of $5 \mathrm{~s}$ at $95^{\circ} \mathrm{C}, 30 \mathrm{~s}$ at $55^{\circ} \mathrm{C}$ for ZNF77 amplification or $60^{\circ} \mathrm{C}$ for GAPDH amplification, and finally $72^{\circ} \mathrm{C}$ for $30 \mathrm{~s}$. A final gradient step from 65 to $95^{\circ} \mathrm{C}$ ( $5 \mathrm{~s}$ per step) was included. Gene expression was analysed using the $\mathrm{ddCt}$ method and differences in gene expression were compared using Mann-Whitney $U$ test (GraphPad 7.0, La Jolla, CA). Experiments were performed in biological and technical triplicates. Data is represented in the manuscript as mean and standard deviation unless other stated.

Evaluation of epithelial barrier function. $16 \mathrm{HBE}$ and $16 \mathrm{HBE}^{\mathrm{rs} 35699176}$ cells were seeded into $1 \mu \mathrm{m}$ Transwell inserts (Corning, USA) at a density of $10^{6}$ cells in 12 well plates. Transepithelial resistance (TER) was evaluated using a EVOM2 ${ }^{\mathrm{mc}}$ Epithelial Volt/Ohm Meter (World Precision Instruments, USA). Experiments were performed at least in biological and technical triplicates. Differences between $16 \mathrm{HBE}$ and $16 \mathrm{HBE}^{\mathrm{rs} 35699176}$ cells were compared for each time point using a Mann-Whitney $U$ test (GraphPad, La Jolla, CA).

Results were confirmed by confocal and phase contrast microscopy. For that, $16 \mathrm{HBE}$ and $16 \mathrm{HBE}^{\mathrm{rs} 35699176}$ cells were seeded at $1 \times 10^{5}$ cells in a 2 -well Idibi chamber (Thistle Scientific, Glasgow, UK) and incubated for $48 \mathrm{~h}$ at $37^{\circ} \mathrm{C}, 5 \% \mathrm{CO}_{2}$ Z-stacks of confocal images were acquired using a fully motorized Leica SP8 laser scanning confocal microscope equipped with a 63XHC PlanApo UVIS CS2 water immersion (NA 1.2) objective. Imaging was performed at $37^{\circ} \mathrm{C}$ in a temperature controlled chamber. Monolayers stained with the plasma membrane Cell Mask Red (ThermoFisher, UK) were excited with a tunable white light laser (70\% power) at $649 \mathrm{~nm}$ and fluorescence was detected between 660 and $750 \mathrm{~nm}$. Z-stacks of confocal images were surface rendered using IMARIS v8.0.1 Image Processing and Visualization software (Bitplane, Switzerland). For phase contrast microscopy, cells were imaged using a Nikon TE-2000E microscope and processed using Metamorph software.

Aspergillus strains. Aspergillus strains (Supplementary Table 3) were cultured at $37^{\circ} \mathrm{C}$ for $48-72 \mathrm{~h}$ on Sabouraud dextrose agar (Oxoid, Basingstoke, UK). Spores were harvested using PBS-containing Tween 20 at $0.1 \%$. Spore stock solutions were washed twice on supplemented MEM without FBS.

A. fumigatus-bronchial epithelial cells co-culture. 16HBE and $16 \mathrm{HBE}^{\mathrm{r} 335699176}$ bronchial epithelial cells were maintained at $37^{\circ} \mathrm{C}, 5 \% \mathrm{CO}_{2}$ in supplemented MEM Epithelial cells were used after the second or third passage for each experiment. For all experiments, $2 \times 10^{5} 16 \mathrm{HBE}$ and $16 \mathrm{HBE}^{\mathrm{rs} 35699176}$ cells were seeded in 24-well plates and incubated for $16 \mathrm{~h}$ (confluence $>90 \%$ ). Cells were then washed twice with supplemented MEM without FBS and cells were serum-starved for $48 \mathrm{~h}$. Monolayers were challenged with $2 \times 10^{4} \mathrm{~A}$. fumigatus spores $(0.1 \mathrm{MOI})$ and incubated for $6 \mathrm{~h}$ (Supplementary table 3). Zero infection controls were made by mock inoculation using supplemented MEM without FBS. After incubation, cell culture supernatants were stored at $-80^{\circ} \mathrm{C}$ until needed and RNA was extracted using the RNAeasy kit (Qiagen).

qPCR. Validated primers (Supplementary Table 2) to measure the expression of Ecadherin (ECAD), occludin (OCLN) and caveolin (CAV2) were purchased from Biorad (Biorad, UK). qPCR amplifications were performed according to manufacturer's instructions and using SensiFASTM SYBR according to manufacturer's instructions. Gene expression was analysed using the ddCt method and differences 
in gene expression were compared using Mann-Whitney $U$ test (GraphPad 7.0, La Jolla, CA). Experiments were performed in biological and technical triplicates.

LDH assay. The Pierce LDH cytotoxicity assay kit (ThermoFisher Scientific Rockford, USA) was used to determine A. fumigatus-mediated cytotoxicity assay according to the manufacturer's instructions. Samples were assessed in technical and biological triplicates. Briefly, $10^{4} 16 \mathrm{HBE}$ and $16 \mathrm{HBE}^{\mathrm{rs} 35699176}$ bronchial epithelial cells were seeded in a 96-well plate and incubated for $16 \mathrm{~h}$ until confluence. Cells were serum-starved for $48 \mathrm{~h}$ as described above and infected with $10^{4} \mathrm{~A}$. fumigatus CEA10 spores. Differences in cell toxicity mediated by $A$. fumigatus were determined at 6,16 and $20 \mathrm{~h}$ post-infection and analysed by $T$-test after normal distribution was confirmed (GraphPad Prism 7.0)

Time-lapse microscopy. Cells were seeded at $2 \times 10^{5}$ cells per well in a 24 -well glass bottom plates (Corning, UK) and incubated for $16 \mathrm{~h}$ until confluent. Cells were serum-starved for $48 \mathrm{~h}$ and then infected with $2 \times 10^{4}$ spores from the $A$. fumigatus strains described in Supplementary Table 3 . The plate was then mounted under a Leica SP8X inverted confocal microscope using a $40 \times$ dry lens objective in a $5 \% \mathrm{CO}_{2}$ environment at $37^{\circ} \mathrm{C}$. Three different positions per well in 3 independent biological and technical replicates were evaluated. Images were captured using the brightfield transmitted light detector of the microscope every $30 \mathrm{~min}$ for $11 \mathrm{~h}$ driven by the Leica LASAF image software. The videos generated by this software were exported as AVI documents and processed with Image J software (NIH) (http://rsb.info.nih.gov/ij). Hyphal length, A. fumigatus germination time point and total growth were measured using Fiji Software (https://fiji.sc/). Differences in A. fumigatus hyphal length and germination time point were determined by $T$-test at fixed time points after confirming normal distribution (GraphPad Prism v7). Differences in A. fumigatus growth curves were calculated using the nonparametric Kruskal-Wallis test using GraphPad Prism 7 software. Experiments were performed in biological and technical triplicates.

Binding of $\boldsymbol{A}$. fumigatus spores. $16 \mathrm{HBE}$ and $16 \mathrm{HBE}^{\mathrm{r} 335699176}$ cells were seeded at $2 \times 10^{5}$ cells per well in a 24 -well plate for $24 \mathrm{~h}$. Plates were washed once with PBS. Cells were incubated for $1 \mathrm{~h}$ at $37^{\circ} \mathrm{C}$ in MEM $+1 \%$ L-Glutamine $+1 \%$ BSA and incubated for $1 \mathrm{~h}$ at $37^{\circ} \mathrm{C}$ to block receptors that could overshadow cell adhesion ${ }^{39}$. After that, medium was replaced with $1 \mathrm{ml} \mathrm{MEM}+1 \% \mathrm{~L}$-glutamine containing $2 \times 10^{5}$ A. fumigatus CEA10 spores. The percentage adhesion was determined after $30 \mathrm{~min}$ and $2 \mathrm{~h}$ incubation time. Cells were then fixed in 3\% paraformaldehyde in PBS for $10 \mathrm{~min}$. Spores were counted using a Nikon TE-2000E microscope with a dry $20 \times$ objective. Five pictures per well in biological and technical triplicates were processed using FIJI software and results were expressed as percent adhered spores. Differences in the percentage of spores binding between 16HBE and $16 \mathrm{HBE}^{\mathrm{rs} 35699176}$ were determined for each time point using two-way ANOVA with multiple comparison test using GraphPad Prism 7.

Adhesion of $\boldsymbol{A}$. fumigatus spores to the extracellular matrix. Cells were seeded at $2 \times 10^{5}$ cells per well in a 24 -well plate for $24 \mathrm{~h}$ and then treated as described in ref. ${ }^{39}$. Quantification of the extracellular matrix layer was performed using a BCA assay (Sigma-Aldrich, Poole, UK). The percentage of adhesion after $30 \mathrm{~min}$ and $2 \mathrm{~h}$ incubation was performed as described before. Differences in protein concentration between cell lines was determined by using an unpaired $T$-test after performing normality test using D'Agostinho and Pearson normality test in GraphPad Prism 7.

\section{Cytokine release. Cytokine quantification produced by $16 \mathrm{HBE}$ and}

$16 \mathrm{HBE}^{\mathrm{rs} 35699176}$ bronchial epithelial cells in the presence of A. fumigatus CEA10 was determined by using the LEGENDplex ${ }^{\text {mit }}$ Human Inflammation Panel (BioLegend, London, UK) and a BD Influx cell sorter machine. This panel allows simultaneous quantification of 13 human inflammatory cytokines/chemokines, including IL-1 $\beta$, IFN- $\alpha$, IFN- $\gamma$, TNF- $\alpha$, MCP-1 (CCL2), IL-6, IL-8 (CXCL8), IL-10, IL-12p70, IL-17A, IL-18, IL-23 and IL-33. Data was analysed by using LEGENDplex data analysis software (http://www.biolegend.com/legendplex/software). Differences in cytokine concentration at $6 \mathrm{~h}$ Aspergillus challenge were performed by using the two-way ANOVA with multiple comparison test (GraphPad, Prism 7.0, La Jolla, CA) in experiments run in biological and technical triplicates. Statistically significant differences were accepted for $P<0.05$.

Germination assay in a cell-free environment. Cells were seeded at $2 \times 10^{5}$ cells per well in a 24 -well plate and incubated for $16 \mathrm{~h}$ at $37^{\circ} \mathrm{C}, 5 \% \mathrm{CO}_{2}$. Cells were then serum-starved for $48 \mathrm{~h}$ and supernatants were collected, centrifuged for $3 \mathrm{~min}$ at $1200 \mathrm{rpm}$ to remove cell debris and stored at $-80^{\circ} \mathrm{C}$ until use. For analysis, samples were thawed on ice and transferred to a 24 -well glass bottomed plate and infected with $2 \times 10^{4}$ spores of the Aspergillus strains. Percentage germination was estimated at 4,5 and $6 \mathrm{~h}$ post-inoculation at $37 \mathrm{C}, 5 \% \mathrm{CO}_{2}$ using a total of 15 images per well by using a Nikon TE-2000E microscope with a $63 \times$ lens and processed using Metamorph software. Percentage spore germination was estimated using the cell counter application in Fiji software. Experiments were performed in technical and biological triplicates including germination in MEM serum-free media as control. Differences in the percentage of germination were calculated by one-way ANOVA with multiple comparison test using GraphPad Prism 7 software.

Internalization assay. 16HBE and 16HBErs35699176 cells were seeded in 24-well glass bottom plates as described. Cells were then challenged with $10^{5} \mathrm{~A}$. fumigatus CEA10 spores-GFP in serum-free media and, incubated for 2, 4 and $6 \mathrm{~h}$ at $37 \mathrm{C}, 5 \%$ $\mathrm{CO}_{2}$. Infected monolayers were stained with Cell Mask as previously described. Cells were then fixed with $3 \%$ formaldehyde and 3D images were obtained using a confocal laser scanning microscope. Spores inside and outside the epithelial monolayer were automatically counted using IMARIS v8.0.1 (Bitplane) software. Statistical analyses were performed by two-way ANOVA with multiple comparisons test using GraphPad Prism. Experiments were performed in biological and technical triplicates.

Heat-inhibition assays. Cell culture supernatants were heat-treated for $10 \mathrm{~min}$ at $95^{\circ} \mathrm{C}$ and then cooled at room temperature. Germination experiments were performed using A. fumigatus CEA10 as described above. Statistical analyses were performed by two-way ANOVA with multiple comparisons using GraphPad Prism. Experiments were performed in biological and technical triplicates.

Secretome analysis. $16 \mathrm{HBE}$ and $16 \mathrm{HBE}^{\mathrm{r} 335699176}$ cells $\left(1 \times 10^{6}\right.$ cells per well $)$ were seeded in 6-well plates for $24 \mathrm{~h}$ at $37^{\circ} \mathrm{C}$ and $5 \% \mathrm{CO}_{2}$. Cells were then washed 10 times with $3 \mathrm{ml}$ serum-free medium and incubated for $48 \mathrm{~h}$. At the time of the experiment, medium was replaced with fresh $3 \mathrm{ml}$ non-supplemented MEM and incubated for $6 \mathrm{~h}$. Cell culture supernatants were then collected and centrifuged at $12,000 \mathrm{rpm}$ for $30 \mathrm{~min}$ to remove cell debris. Experiments consisted of 3 biological replicates. Cell culture supernatants were prepared for mass spectrometry using a modified filter-aided sample preparation (FASP) method with modifications. Approximately $3 \mathrm{ml}$ cell culture supernatants were concentrated to $20 \mu \mathrm{l}$ using Microcon-30 kDa centrifugal filter units (Merck Millipore). Protein concentration was determined using a Millipore Direct Detect ${ }^{\circledR}$ spectrometer at AM1. LysC was used for the initial digestion at a ratio of 1:30 (enzyme:protein). After $3 \mathrm{~h}$, the urea concentration was dropped from a concentration of $6 \mathrm{M}$ to $1 \mathrm{M}$ with the addition of Tris- $\mathrm{HCl}, \mathrm{pH}$ 8. The proteins were then digested with trypsin at a ratio of 1:50 (enzyme:protein). After digestion, peptides were collected and the samples were desalted with OLIGO ${ }^{m} \mathrm{R} 3$ reversed-phase media.

Digested samples were analysed by LC-MS/MS using an UltiMate ${ }^{\circledast} 3000$ Rapid Separation LC (RSLC, Dionex Corporation, Sunnyvale, CA) coupled to an Q Exactive $^{\text {min }}$ HF Hybrid Quadrupole-Orbitrap ${ }^{\text {tws }}$ mass spectrometer (ThermoFisher Scientific, Waltham, MA, USA). Peptide mixtures were separated using a $90 \mathrm{~min}$ gradient, from $92 \% \mathrm{~A}(0.1 \% \mathrm{FA}$ in water) and $8 \% \mathrm{~B}(0.1 \% \mathrm{FA}$ in acetonitrile) to $33 \% \mathrm{~B}$, in $66 \mathrm{~min}$ at $300 \mathrm{nl}$ permin, using a $250 \mathrm{~mm} \times 75 \mu \mathrm{m}$ i.d. $1.7 \mathrm{mM}$ BEH C18 analytical column (Waters, Wilmslow, UK). Peptides were selected for fragmentation automatically by data dependent analysis.

The acquired MS data was analysed using Progenesis LC-MS (v4.1, Nonlinear Dynamics, Newcastle upon Tyne, UK). Features with charges $\geq+5$ were masked and excluded from further analyses, as were features with less than 3 isotope peaks. The resulting peak lists were searched against the Uniprot Human database (version 20151111) using Mascot v2.5.1, (Matrix Science, Boston, USA). The Mascot results were imported into Progenesis LC-MS for annotation of peptide peaks. Network analysis and GO of dysregulated proteins was performed using String v9.0 (http://string-db.org). The induced network was further visualised by using Cytoscape v3.2.1.

RNA-seq analysis. Changes in the expression between $16 \mathrm{HBE}$ and $16 \mathrm{HBE}^{\mathrm{rs} 35699176}$ cells exposed to A. fumigatus for $6 \mathrm{~h}$ at a $0.1 \mathrm{MOI}$ were analysed by RNA-seq. RNA was extracted using RNAeasy kit (Qiagen, Manchester, UK). Experiments consisted of 3 biological replicates. Strand-specific RNA-seq libraries were prepared using the Illumina workflow with the TruSeq ${ }^{\oplus}$ Stranded mRNA Sample Preparation Kit (Illumina, San Diego, USA). Paired-end reads were generated from each sample. Up to $78 \mathrm{M}$ of total reads were obtained from each sample. The FASTQ files generated by HiSeq Illumina 4000 platform were analysed with FastQC and any low quality reads and contaminated barcodes and primers were filtered and trimmed with Trimmomatic v3.2. All libraries were aligned to the hg19 ch37 assembly of human genome using TopHat-2.1.0 (https://ccb.jhu.edu/ software/tophat/index.shtml) and only the best-mapped reads were collected for differential analysis. The mapped reads were counted with HTSeq against Gencode_v16.gtf (https://www.gencodegenes.org). Differentially expressed (DE) genes were identified between each pair of different levels cell type (16HBE and 16HBE rs35699176) with the DESeq2 package (https://bioconductor.org). GO enrichment analysis was performed using String v9.0 (http://string-db.org).

rs35699176 genotyping. DNA from 21 bronchoalveolar lavages from patients with known fungal loads (previously determined using metagenomics sequencing) (Local Research Ethics Committee REC reference no 11/NW/0175) was used for ZNF77 genotyping ${ }^{13}$. Patient demographics are shown in Table 1. Samples were sequenced as detailed in Generation of $16 \mathrm{HBE}^{\mathrm{rs} 35699176}$ bronchial epithelial cells section using primers rs35699176-3 and rs35699176-4 and analysed using Chromas-Lite (http://chromas-lite.software.informer.com). Associations between 
genotype and fungal load were analysed by $T$-test and FET using GraphPad Prism 7.0 (La Jolla, CA, USA).

For validation, DNA samples from sputum of 45 ABPA patients were used for genotyping (Table 2, ManArts M2016-45). Aspergillus burden in sputum samples was determined by Aspergillus real-time PCR (Progenie Aspergillus FUMI, Werfen, UK) at the National Aspergillosis Center (Manchester, UK). Correlation between genotype and PCR result was determined by Chi-square and Fisher exacts test using GraphPad Prism 7.0.

All patients in the study provided their informed consent according to the Biobank regulations.

\section{Data availability}

All relevant data supporting the findings of the study are available in this article and its Supplementary Information files, or from the corresponding authors upon request, with restriction of data that would compromise patient confidentiality. The RNA-seq data used in this study have been deposited in the EMBL Arrayexpress platform under the accession number E-MTAB-7066 [https://www.ebi.ac.uk/arrayexpress/experiments/EMTAB-7066]. Secretome data can be accessed in [https://www.figshare.com/s/ adf8b6dbda50aab943fe]. https://doi.org/10.6084/m9.figshare.6833810.

Received: 17 October 2017 Accepted: 27 July 2018

Published online: 20 September 2018

\section{References}

1. Kwon-Chung, K. J. \& Sugui, J. A. Aspergillus fumigatus-what makes the species a ubiquitous human fungal pathogen? PLoS Pathog. 9, e1003743 (2013).

2. Kosmidis, C. \& Denning, D. W. The clinical spectrum of pulmonary aspergillosis. Thorax 70, 270-277 (2015).

3. Bongomin, F., Gago, S., Oladele, R. O. \& Denning, D. W. Global and multinational prevalence of fungal diseases-estimate precision. J. Fungi 3, E57 (2017).

4. Perfect, J. R. et al. The impact of culture isolation of Aspergillus species: a hospital-based survey of aspergillosis. Clin. Infect. Dis. 33, 1824-1833 (2001).

5. Warris, A. \& Verweij, P. E. Clinical implications of environmental sources for Aspergillus. Med. Mycol. 43(Suppl. 1), S59-S65 (2005).

6. Ohba, H. et al. Clinical characteristics and prognosis of chronic pulmonary aspergillosis. Resp. Med. 106, 724-729 (2012).

7. Agarwal, R. \& Chakrabarti, A. Allergic bronchopulmonary aspergillosis in asthma: epidemiological, clinical and therapeutic issues. Future Microbiol. 8, 1463-1474 (2013).

8. Agarwal, R. et al. Allergic bronchopulmonary aspergillosis: review of literature and proposal of new diagnostic and classification criteria. Clin. Exp. Allergy 43, 850-873 (2013).

9. Agarwal, R., Nath, A., Aggarwal, A. N., Gupta, D. \& Chakrabarti, A. Aspergillus hypersensitivity and allergic bronchopulmonary aspergillosis in patients with acute severe asthma in a respiratory intensive care unit in North India. Mycoses 53, 138-143 (2010).

10. Denning, D. W. et al. Fungal allergy in asthma-state of the art and research needs. Clin. Transl. Allergy 4, 14 (2014).

11. Knutsen, A. P. et al. Fungi and allergic lower respiratory tract diseases. J. Allergy Clin. Immunol. 129, 280-291 (2012).

12. Zander, D. S. Allergic bronchopulmonary aspergillosis: an overview. Arch. Pathol. Lab. Med. 129, 924-928 (2005).

13. Fraczek, M. G. et al. Corticosteroid treatment is associated with increased filamentous fungal burden in allergic fungal disease. J. Allergy Clin. Immunol. 142, 407-414 (2017).

14. Chmiel, J. F. et al. Antibiotic management of lung infections in cystic fibrosis. II. Nontuberculous mycobacteria, anaerobic bacteria, and fungi. Ann. Am. Thorac. Soc. 11, 1298-1306 (2014).

15. Denning, D. W., Pleuvry, A. \& Cole, D. C. Global burden of allergic bronchopulmonary aspergillosis with asthma and its complication chronic pulmonary aspergillosis in adults. Med. Mycol. 51, 361-370 (2013).

16. Carvalho, A. et al. Polymorphisms in toll-like receptor genes and susceptibility to pulmonary aspergillosis. J. Infect. Dis. 197, 618-621 (2008).

17. Knutsen, A. P., Kariuki, B., Consolino, J. D. \& Warrier, M. R. IL-4 alpha chain receptor (IL-4Ralpha) polymorphisms in allergic bronchopulmonary sspergillosis. Clin. Mol. Allergy 4, 3 (2006).

18. Overton, N. L., Denning, D. W., Bowyer, P. \& Simpson, A. Genetic susceptibility to allergic bronchopulmonary aspergillosis in asthma: a genetic association study. Allergy Asthma Clin. Immunol. 12, 47 (2016).

19. Saxena, S., Madan, T., Shah, A., Muralidhar, K. \& Sarma, P. U. Association of polymorphisms in the collagen region of SP-A2 with increased levels of total
IgE antibodies and eosinophilia in patients with allergic bronchopulmonary aspergillosis. J. Allergy Clin. Immunol. 111, 1001-1007 (2003).

20. Vaid, M. et al. Distinct alleles of mannose-binding lectin (MBL) and surfactant proteins A (SP-A) in patients with chronic cavitary pulmonary aspergillosis and allergic bronchopulmonary aspergillosis. Clin. Chem. Lab. Med. 45, 183-186 (2007).

21. Greene, C. S. et al. Understanding multicellular function and disease with human tissue-specific networks. Nat. Genet. 47, 569-576 (2015).

22. Wiesner, D. L. \& Klein, B. S. Lung epithelium: barrier immunity to inhaled fungi and driver of fungal-associated allergic asthma. Curr. Opin. Microbiol. 40, 8-13 (2017)

23. Bertuzzi, M. et al. Anti-Aspergillus activities of the respiratory epithelium in health and disease. J. Fungi 4, E8 (2018).

24. Croft, C. A., Culibrk, L., Moore, M. M. \& Tebbutt, S. J. Interactions of Aspergillus fumigatus conidia with airway epithelial cells: a critical review. Front. Microbiol. 7, 472 (2016).

25. Gresnigt, M. S., Netea, M. G. \& van de Veerdonk, F. L. Pattern recognition receptors and their role in invasive aspergillosis. Ann. N. Y. Acad. Sci. 1273 , 60-67 (2012).

26. Sheppard, D. C. Molecular mechanism of Aspergillus fumigatus adherence to host constituents. Curr. Opin. Microbiol. 14, 375-379 (2011).

27. Wasylnka, J. A. \& Moore, M. M. Aspergillus fumigatus conidia survive and germinate in acidic organelles of A549 epithelial cells. J. Cell Sci. 116, 1579-1587 (2003)

28. Wasylnka, J. A. \& Moore, M. M. Uptake of Aspergillus fumigatus conidia by phagocytic and nonphagocytic cells in vitro: quantitation using strains expressing green fluorescent protein. Infect. Immun. 70, 3156-3163 (2002).

29. Menzies, D., Holmes, L., McCumesky, G., Prys-Picard, C. \& Niven, R. Aspergillus sensitization is associated with airflow limitation and bronchiectasis in severe asthma. Allergy 66, 679-685 (2011).

30. Jolink, $\mathrm{H}$. et al. $\mathrm{T}$ helper 2 response in allergic bronchopulmonary aspergillosis is not driven by specific Aspergillus antigens. Allergy 70, 1336-1339 (2015).

31. Kojima, T. et al. Regulation of tight junctions in upper airway epithelium. BioMed. Res. Int. 2013, 947072 (2013).

32. Palmer, C. N. et al. Common loss-of-function variants of the epidermal barrier protein filaggrin are a major predisposing factor for atopic dermatitis. Nat. Genet. 38, 441-446 (2006).

33. Yoshida, K. et al. Distinct behavior of human Langerhans cells and inflammatory dendritic epidermal cells at tight junctions in patients with atopic dermatitis. J. Allergy Clin. Immunol. 134, 856-864 (2014).

34. de Boer, W. I. et al. Altered expression of epithelial junctional proteins in atopic asthma: possible role in inflammation. Can. J. Physiol. Pharmacol. 86, 105-112 (2008).

35. Wan, H. et al. Der $\mathrm{p} 1$ facilitates transepithelial allergen delivery by disruption of tight junctions. J. Clin. Invest. 104, 123-133 (1999).

36. Sheppard, D. C. \& Filler, S. G. Host cell invasion by medically important fungi. Cold Spring Harb. Perspect. Med. 5, a019687 (2014).

37. Warris, A. The biology of pulmonary Aspergillus infections. J. Infect. 69(Suppl. 1), S36-S41 (2014).

38. Carvalho, A. et al. Inflammation in aspergillosis: the good, the bad, and the therapeutic. Ann. N. Y. Acad. Sci. 1273, 52-59 (2012).

39. Bromley, I. M. \& Donaldson, K. Binding of Aspergillus fumigatus spores to lung epithelial cells and basement membrane proteins: relevance to the asthmatic lung. Thorax 51, 1203-1209 (1996).

40. DeHart, D. J., Agwu, D. E., Julian, N. C. \& Washburn, R. G. Binding and germination of Aspergillus fumigatus conidia on cultured A549 pneumocytes. J. Infect. Dis. 175, 146-150 (1997).

41. Wasylnka, J. A. \& Moore, M. M. Adhesion of Aspergillus species to extracellular matrix proteins: evidence for involvement of negatively charged carbohydrates on the conidial surface. Infect. Immun. 68, 3377-3384 (2000).

42. Bao, Z. et al. Evidence for the involvement of cofilin in Aspergillus fumigatus internalization into type II alveolar epithelial cells. BMC Microbiol. 15, 161 (2015).

43. Han, X. et al. $\beta-1,3$-Glucan-induced host phospholipase D activation is involved in Aspergillus fumigatus internalization into type II human pneumocyte A549 cells. PLoS ONE 6, e21468 (2011).

44. Chen, F. et al. Transcriptome profiles of human lung epithelial cells A549 interacting with Aspergillus fumigatus by RNA-Seq. PLoS ONE 10, e0135720 (2015).

45. Blekhman, R. et al. Host genetic variation impacts microbiome composition across human body sites. Genome Biol. 16, 191 (2015).

46. Mulcahy, M. E. \& McLoughlin, R. M. Host-bacterial crosstalk determines Staphylococcus aureus nasal colonization. Trends Microbiol. 24, 872-886 (2016).

47. Smeekens, S. P., van de Veerdonk, F. L., Kullberg, B. J. \& Netea, M. G. Genetic susceptibility to Candida infections. EMBO Mol. Med. 5, 805-813 (2013). 
48. Ng, T. T., Robson, G. D. \& Denning, D. W. Hydrocortisone-enhanced growth of Aspergillus spp.: implications for pathogenesis. Microbiology 140, 2475-2479 (1994).

49. Sebastian, V. et al. New applications for known drugs: human glycogen synthase kinase 3 inhibitors as modulators of Aspergillus fumigatus growth. Eur. J. Med. Chem. 116, 281-289 (2016).

50. Netea, M. G. et al. Aspergillus fumigatus evades immune recognition during germination through loss of toll-like receptor-4-mediated signal transduction. J. Infect. Dis. 188, 320-326 (2003).

51. Tomee, J. F., Wierenga, A. T., Hiemstra, P. S. \& Kauffman, H. K. Proteases from Aspergillus fumigatus induce release of proinflammatory cytokines and cell detachment in airway epithelial cell lines. J. Infect. Dis. 176, 300-303 (1997).

52. Cunha, C. et al. IL-10 overexpression predisposes to invasive aspergillosis by suppressing antifungal immunity. J. Allergy Clin. Immunol. 140, 867-870 (2017).

53. Brouard, J. et al. Influence of interleukin-10 on Aspergillus fumigatus infection in patients with cystic fibrosis. J. Infect. Dis. 191, 1988-1991 (2005).

54. Denning, D. W. et al. High-frequency triazole resistance found in nonculturable Aspergillus fumigatus from lungs of patients with chronic fungal disease. Clin. Infect. Dis. 52, 1123-1129 (2011).

55. Stevens, D. A. et al. A randomized trial of itraconazole in allergic bronchopulmonary aspergillosis. N. Engl. J. Med. 342, 756-762 (2000).

56. Barbosa, M. S. et al. Glyceraldehyde-3-phosphate dehydrogenase of Paracoccidioides brasiliensis is a cell surface protein involved in fungal adhesion to extracellular matrix proteins and interaction with cells. Infect. Immun. 74, 382-389 (2006).

57. Grzela, K., Litwiniuk, M., Zagorska, W. \& Grzela, T. Airway remodeling in chronic obstructive pulmonary disease and asthma: the role of matrix metalloproteinase-9. Arch. Immunol. Ther. Exp. 64, 47-55 (2016).

58. Overton, N. L. D., Brakhage, A. A., Thywissen, A., Denning, D. W. \& Bowyer, P. Mutations in EEA1 are associated with allergic bronchopulmonary aspergillosis and affect phagocytosis of Aspergillus fumigatus by human macrophages. PLoS ONE 13, e0185706 (2018).

59. Ran, F. A. et al. Genome engineering using the CRISPR-Cas9 system. Nat. Protoc. 8, 2281-2308 (2013).

60. Cozens, A. L. et al. CFTR expression and chloride secretion in polarized immortal human bronchial epithelial cells. Am. J. Respir. Cell Mol. Biol. 10, 38-47 (1994).

\section{Acknowledgements}

The research leading to these results has been funded by the Fungal Infection Trust. We would like to thank Dr. Ping Wang of the Bioinformatics Core Facilities at the University of Manchester for providing support analysing the RNA-seq data, Dr. Gareth Howell of the Flow Cytometry Core Facility at the University of Manchester for his assistance in conducting FACS analysis, Dr. Ronan O'Cualain, David Knight and Julian Selley of the Biological Mass Spectrometry Core Facility for their help in performing secretome data analysis, Lea Gregson for her support in cell culture and Darren Thomson for his help in assessing time-lapse microscopy experiments. We would also like to thank the Mycology Reference Centre Manchester for providing some of the strains used in this study and for performing Aspergillus PCRs, Charles Streuli and Martin Humphries for their critical comments, and Marcin Frazer and Livingstone Chishimba for providing the bronchoalveolar DNA samples. This report is independent research supported by the National Institute for Health Research Clinical Research Facility at University Hospital of South Manchester NHS Foundation Trust. The views expressed in this publication are those of the authors and not necessarily those of the NHS, the National Institute for Health Research or the Department of Health. The authors would like to acknowledge the Manchester Allergy, Respiratory and Thoracic Surgery Biobank and the North West Lung Centre Charity for supporting this project. In addition, we would like to thank the study participants for their contribution. S.G. was supported by the Fungal Infection Trust and she is currently funded by the NC3Rs grant: NC/P002390/1. P.B. was sup- ported by MRC grant MR/M02010X/1. N.L.D.O. received support from the Fungal Infection Trust and the National Institute for Health Research South Manchester Respiratory and Allergy Clinical Research Facility at University Hospital of South Manchester NHS Foundation Trust. N.B.G. is supported by the Libyan Ministry of Higher Education and Scientific Research.

\section{Author contributions}

S.G. and P.B. designed and performed the experiments, analysed data and prepared the manuscript. N.O. provided technical support to S.G., N.B.G. and N.R. performed the confocal image analysis and processing of the epithelial monolayers, L.N.F. analysed Aspergillus fungal loads in respiratory samples from patients at the National Aspergillosis Center, helped with patient selection for genotyping studies and preparation of the manuscript, D.W.D. and P.B. conceived the project, designed and supervised this study and prepared the manuscript.

\section{Additional information}

Supplementary Information accompanies this paper at https://doi.org/10.1038/s41467 018-06148-7.

Competing interests: N.B.G., L.N.F., D.W.D. and P.B. declare the following competing interests related to this research. N.B.G. has been paid for talks on behalf of Nawgen SL. L.N.F. has been paid travel expenses and she has written and presented on resistance monitoring using pyrosequencing for Gilead GAIN education programme. D.W.D. and family hold founder shares in F2G Ltd., an antifungal discovery company and in Novocyt, which markets the Myconostica real-time molecular assays. D.W.D. has a patent for fungal infection assays that has been externally licensed; he acts or has recently acted as a consultant to Astellas, Sigma Tau, Basilea, Scynexis, Cidara, Biosergen, Quintilles, and Pulmocide; and in the last 3 years he has been paid for talks on behalf of Astellas, Dynamiker, Gilead, Merck, and Pfizer. P.B. is a founder of Alergenetica SL. and Syngenics Ltd. None of the other authors have a relevant financial conflict of interest. S. G. is a council member of the International Society of Human and Medical Mycology (ISHAM). N.B.G. has been the head of the Libyan Medical Laboratory Association. N.R. has been a President of the British Mycological Society, a Fellow of the Royal Society of Biology and of the Royal Microscopical Society. D.W.D. is a longstanding member of the Infectious Disease Society of America Aspergillosis Guidelines Group, the European Society for Clinical Microbiology and Infectious Diseases Aspergillosis Guidelines Group and the British Society for Medical Mycology Standards of Care Committee. None of the other authors have a relevant non-financial conflict of interest.

Reprints and permission information is available online at http://npg.nature.com/ reprintsandpermissions/

Publisher's note: Springer Nature remains neutral with regard to jurisdictional claims in published maps and institutional affiliations.

Open Access This article is licensed under a Creative Commons Attribution 4.0 International License, which permits use, sharing, adaptation, distribution and reproduction in any medium or format, as long as you give appropriate credit to the original author(s) and the source, provide a link to the Creative Commons license, and indicate if changes were made. The images or other third party material in this article are included in the article's Creative Commons license, unless indicated otherwise in a credit line to the material. If material is not included in the article's Creative Commons license and your intended use is not permitted by statutory regulation or exceeds the permitted use, you will need to obtain permission directly from the copyright holder. To view a copy of this license, visit http://creativecommons.org/ licenses/by/4.0\%

(c) The Author(s) 2018 